\title{
ECOCRITICISM AND POSTCOLONIALISM IN AMITAV GHOSH'S THE HUNGRY TIDE
}

\section{DR. SUDDHOJIT CHATTERJI}

Assistant Teacher, +2 Govt. High School, Kathikund, Dumka, Jharkhand

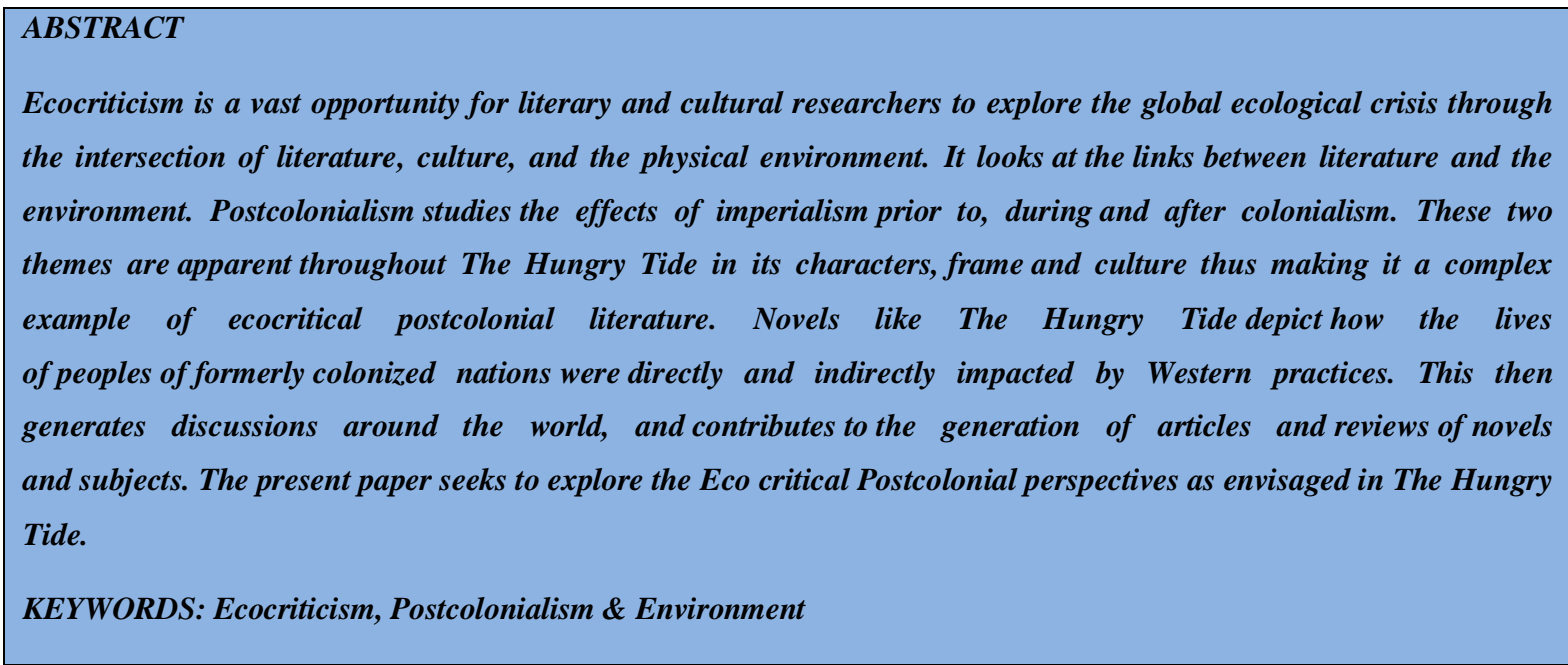

Received: Jun 20, 2021; Accepted: Jul 10, 2021; Published: Jul 23, 2021; Paper Id: IJELDEC20218

\section{INTRODUCTION}

In eco-critical literature, the relationship between the environment and literature is examined. Its main purpose is to educate people about environmental issues and hopefully get help. With time, ecocriticism grew in importance due to their environmental policy agenda. This is a crucial step toward understanding the current environmental crisis, but it will only work if more people become aware of it. To change this mindset, the world needs education and, positively, a change in ethics.

In the Hungry Tide, the reader is made aware of the environmental crisis in the Sundarbans caused by occidental culture. In addition to this, corruption and apathetic attitude of the government in the Sundarbans, and its impact upon the people who reside there, is also depicted. Through Postcolonial literature previously colonized nations express their situation, and bring awareness of their predicament on a global scale.

The Hungry Tide (2004), Amitav Ghosh's fifth novel, is a contemporary story of dislocations, disjunctions and destabilization. It has been well-acknowledged as an ecological novel. It is a unique novel with the amalgamation of anthropology, environmentalism, migration, travel, ethnography, photography and landscape wrapped under the veil of fiction.

"The novel abounds in information about natural history, the authenticity of which need not be questioned from a writer with a reputation for meticulous research and one who is an anthropologist by training. However, it is the movement towards a vision at the end, which is more interesting and enlightening. What Piya realizes should be realized by all the eco-critics. After the storm and Fokir's death, Piya goes away only to return with funds and a 
proposal for a research project. Piya wants to work in consolation with the local fishermen so that the burden of conservation would not fall on those who could least afford it. She wants the project to run under the sponsorship of the Badabon Trust. It is a small gesture but significant nevertheless. She refuses to exclude the man at the grassroots from her work as a conservationist. She is aware that without Fokir's particular knowledge of his environment, she would have remained ignorant of the river dolphins in the tide country and so would the rest of the world. (Thakur 70-71)"

Ghosh raises serious apprehension about the decay and degradation of the rich environment of the Sunderbans by careless activities of the humans. Besides raising issues of environment and ecology, the novel vigorously takes up the cause of the subaltern settlers and migrants. At the center of the text is the plight of the poor living in the most uninhabitable forests of the Sunderbans in West Bengal, particularly the island of Morichjhapi. "The novel demonstrates how environmentalism and conservation, nevertheless, has its own costs, and it explores the ethical dilemmas that result from this". (Rahman 94)

We find different views about the environment in the characters in the novel The Hungry Tide. Some have a more environmentally conscious perspective, while others have the attitude of the West. This difference in opinion is important because it is compatible with everyone despite their personal views, and allows them to learn about other perspectives on the topic. Among the most fascinating ways, The Hungry Tide distinguishes it from other literature is by making the environment itself a character in the form of Bon Bibi. For this reason, the conflict between environments and other characters becomes tangible rather than figurative. Nature appears at its most beautiful and ugliest.

“Amitav Ghosh creates emotional dilemma among us as to whom to support” (Shikha).

According to Imperialism, countries, people, and resources that advance the progress of Western civilization are more important than everything else

"The current civilization is divided into two factions - the so-called savage or indigenous people and their socalled civilized ex-ruling people. This division has been created by the West to make a marginalization between the colonizers and the colonized. The class difference between the civilized and the savage is so high that the relationship between these peoples has been formed and developed is based on the dependence of the ruled upon the mercy of the rulers. This 'ambivalent relationship' gradually breeds 'binary culture', which ultimately obstructs the smooth running of social and political development where the question of civilization is itself a far-reaching rolling stone" (Abul 120-121).

There are many lingering effects of imperialism evident in The Hungry Tide by addressing the cultural and political issues of the time. Ghosh gives his characters depth and authenticity by blending these diverse perspectives. It seems the natives no longer cared about coexisting with nature; instead, they tried to use it to obtain power and money. This concept of dominance over lesser things is very Western. Imperialism has corrupted the government as well, which can be seen in the way the Forest Department is portrayed.

Each character in The Hungry Tide grows up and is raised differently. The main character Piya grew up in the United States, but has a deep sense of connection to nature. Having grown up in the tide country, Moyna has fully embraced Western ideals. Fokir grew up in the tide country as well, and is equally connected to nature. Despite his roots in the tide country, Kanai is very much a city man. The different frames of reference expressed in the novel, represent meticulously the diversity present in the characters. The disagreement and disparity between all of these frames of reference produce traction. But that does not mean that incompatible views cannot work together. We see Piya and Fokir 
working together frequently. Most notably is the crab fishing and GPS scene where Piya realizes that it is possible for vastly different practices to be complimentary, "But that it had proved possible for two such different people to pursue their own ends simultaneously_ people who could not exchange a word with each other and had no idea of what was going on in the other one's head — was far more than surprising: it seemed almost miraculous" (Ghosh 118).

Numerous forms of postcolonialism, is depicted in the novel such as the agony of sundarbans refugees returning home, local people like illiterate Fokir and Horen, educated Nirmal and Nilima with their postnationalist dreams, and the disaster that is wreaking havoc on the lives of local people on Lusibari island. Sir Daniel Hamilton, a British idealist, purchased 10,000 acres of the Sundarbans and urged disadvantaged people to come and inhabit the area for free on the condition that there be no caste system or tribal self-rule. Despite the crocodiles, tigers, snakes and dangerous tides, despite the fact that they were farmers and would now have to become fishermen, many desperately poor people noticed his call and arrived. They moved to this commune in three waves: descended from the first settlers who came in the 1920 s, in 1947 after partition and in 1971 after the Bangladesh war. They helped Hamilton establish a semi- communist region where the inhabitants shared their possessions. Thus despite its small size, the island of Lusibari supported a population of several thousand people. Kanai, a translator from Delhi who is visiting her aunt Nilima Bose, and Piyali Roy, a cytologist and the daughter of Bengali immigrants, are both interested in studying marine mammals in the Sundarbans. All of these people are an outcome of the postcolonial era.

In the novel, the entries in Nirmal's diary describing Morichjhapi and Kusum, Fokir's mother and her troubles provide a true reality of the Sunderbans. When the water and food supplies were interrupted, the refugees fought for survival, became the prey of Morichjhapi to the islands to force the immigrant to escape. The question of rootlessness and deprived classes who were the subaltern agents, remain powerless and they pay attention to the policemen formulating their messages, say that their lives and experience was worth than filth.

Some instances in the novel such as the slaughter, the tiger's assassination of Kusum's father and Fokir's defenselessness to the condition official, depict the subaltern as well as the marginalized people's predicament.

The island's inhabitants were facing starvation and disaster as a result of the river's salty water, which rendered the soil barren. This compelled them to pursue fish culture and hunting in order to cope with the calamity that had been placed upon them. Because of this, the climate of sundarbans was affected. The fishermen used the net for fishing and took out everything they wanted, from the water. And then they took out the lucrative prawn to get a fair amount. Through that route, they took out the fresh water of spawn, which created a complete ecological disaster. This would disturb the complete fishing life of the sundarbans. In order to draw the attention of the general public, Amitav Ghosh wishes to safeguard human life and the Sundarbans' wildlife habitat.

Prawns don't breed inside ponds; they need open water. What the fishermen do is go out with microscopically fine mesh nets and sieve the water. They take out everything that they get, and then they go through all the debris and pick out the prawn spawn. They pick out only the lucrative little bits of prawn spawn for which they get paid a fair amount. However, in the process, they completely clear the water of the spawn of every other fish species as well, and this creates a complete ecological disaster, whereby the entire fish life of the Sundarbans will soon be decimated. There is an incredible urgency about what is happening here and around people's lives. (Ghosh, the UN Chronicle) 
The settlement of human beings in forested land is clearly depicted in The Hungry Tide. He focuses on Sundarbans Island, where the lives of human beings are always under the fear of death The Sundarbans is a place where beauty is harsh and vengeful; this makes human existence an intense task and full of struggle. Sundarbans is a tide country where water comes to the island every day and disappears later, with reptiles, snakes and man-eating tigers. In this novel, the readers find the terrifying beauty of the river and forest.

"....beauty is nothing but the start of terror we can hardly bear, and we adore it because of the serene scorn it could kill us with..." (Ghosh, The Hungry Tide 69)

In The Hungry Tide, it's crucial to consider the relationship between postcolonialism and ecocriticism. The effects of colonialism are to blame for many environmental issues. Similarly, many of the solutions to those same problems are devised by those seeking to reduce or eliminate their consequences. In the novel, postcolonialism and ecocriticism are intricately linked. The battle between tigers and humans is exemplified by the tigers. The novel's Western protagonists desire to save the tigers no matter how many people they have killed. People who have lived in the Sundarbans their entire lives, on the other hand, want to kill the tigers because so many of their neighbours have been slain. The Indians had tried a variety of tactics to encourage the tigers to stop murdering people, but none of them had worked. The Western characters are blind to this and categorize the locals as savages who need to be trained about proper social behaviour. Another intriguing perspective is that the tigers represent nature's retaliation against the inhabitants, who have gotten overly selfish and westernized. According to the story, fishermen have adopted unsustainable fishing tactics in order to make a profit, "These new nylon nets, which they use to catch chingrir meen - the spawn of tiger prawns. The nets are so fine that they catch the eggs of all the other fish as well” (Ghosh 111-112). This is further proof of imperialism's preference for money over nature, even after the colonists have departed. This, among other things, could be interpreted as a rebellion against nature. As a result, the environment has decided to punish them in the guise of tigers and storms in the form of Bon Bibi.

The Hungry Tide deftly employs postcolonial and ecocritical theories to inspire readers to view the world through a less Westernized viewpoint. It offers traditionally marginalized groups, such as the environment and indigenous peoples, a voice; novels like The Hungry Tide bring much-needed global awareness to the world. Throughout history, Western culture has silenced and marginalized the environment and indigenous peoples. The Hungry Tide raise awareness of these groups and their plight all around the world.

\section{REFERENCES}

1. Azad, Abul Kalam. "Treatment of Subaltern and Diaspora in Amitav Ghosh's Fiction from the Postcolonial Perspective." Banglavision Research Journal 14.1 (2014): 119-132. Print.

2. Ghosh, Amitav. The Hungry Tide. Boston: Houghton Mifflin, 2005. Print.

3. Rahman, Gulrez Roshan. “An Eco-critical Reading of Amitav Ghosh's The Hungry Tide”. Research: A Journal of English Studies. Vol. II, No. 1, Spring 2011.

4. Shikha, Kumari. "Ecocriticism in Indian Fiction." Worldlitonline.net. Jan. 2011. Web. 15 Feb. 2015

5. Thakur, Akhileshwar. "Amitav Ghosh's The Hungry Tide: A Critique of Nature

6. Culture Duality". Literary Perspectives. Vol. 9, No. 1, January 2014.

7. "The Chronicle Interview: Amitav Ghosh" UN Chronicle Online Edition http://www.un.org/Pubschronicle2005/issue40405p48.html 
8. Gaikwad, Nikita, Yogita Mistry, and Kiran Inamdar. "Design and Implementation of Energy Efficient Environment Monitoring System." International Journal of Electronics, Communication \& Instrumentation Engineering Research and Development (IJECIERD), Vol. 6, Issue 3, pp, 1- 6

9. Radhi, NABAA S., and Z. A. I. N. A. B. Al-Khafaji. "Investigation biomedical corrosion of implant alloys in physiological environment." Int. J. Mech. Prod. Eng. Res. Dev 8.4: 247-256.

10. Kushwah, Virendra Singh, Sandip Kumar Goyal, and Priusha Narwariya. "A survey on various fault tolerant approaches for cloud environment during load balancing." Int J Comput Netw Wirel Mobile Commun 4.6 : 25-34.

11. Mourya, Sadhika, and Sandipan Chakraborty. "Assessment And Impact of Ambient Air Quality in Sonepur-Bazari Opencast Project-An Approach Towards Sustainable Environment, Raniganj Coalfield, Barddhaman, West Bengal, India." International Journal of Applied and Natural Sciences (IJANS) 5.4: 83-92.

12. Mahajan11, R. I. N. I., and Dheerendra Singh. "Step By Step Securing Cloud Environment." International Journal of General Engineering and Technology (IJGET) 6: 47-54.

13. Senthilkumar, P. "Environmental Effect of Using Diesel On Waste Plastic Oil Fueled In Diesel Engine." International Journal of Mechanical Engineering (IJME) 7. 3, pp, 18. 
